\title{
A constituição social da subjetividade: Notas sobre Central do Brasil
}

Roseli A Cação Fontana*

RESUMO: Que professoras/professores estamos sendo, em tempos difíceis como os de hoje, quando a escola caminha para funcionar, cada vez mais como empresa, sendo a educação, esvaziada de seu significado humano, sua mercadoria? Nesse processo de formação e nas relações de trabalho vividas, quem estamos sendo? Quem estamos chegando a ser? Como nos re-conhecemos? Neste escrito, em interlocução com Vigotski, Bakhtin, Politzer e com o filme de Walter Salles - Central do Brasil - aproximo-me dessas questões, não para respondê-las, mas para encará-las nos dramas singulares vividos, por nós com nossos outros, em relações sociais de exclusão e de solidão, de desigualdade e violência, de modernizações impostas e preconceito.

Palavras-chave: Subjetividade, processos de constituição do sujeito, drama, narrativa

“... o mais importante e bonito, do mundo, é isto: que as pessoas não estão sempre iguais, ainda não foram terminadas - mas que elas vão sempre mudando. Afinam ou desafinam."

(Guimarães Rosa - Grande Sertão: Veredas)

Como chegamos a ser o que somos? Entre afinações e desafinações, como vamos nos constituindo?

* Faculdade de Educação/ Unicamp. 
Intrigam-me, essas questões, há tempos. Guiada por Vigotski e Politzer, no campo da Psicologia, e por Bakhtin, no estudo da linguagem, acerquei-me de uma abordagem histórico-cultural da constituição da subjetividade, segundo a qual somente através de nossas relações com outros indivíduos tornamo-nos nós mesmos.

Ao nascer, cada um de nós mergulha na vida social, na história, e vive, ao longo de sua existência, distintos papéis e lugares sociais, carregados de significados - estáveis e emergentes - que nos chegam através dos outros. Mediados por nossos parceiros sociais, próximos e distantes, conhecidos e ignorados, integramo-nos progressivamente nas relações sociais, nelas aprendendo a nos reconhecermos como "pessoas".

Os lugares que ocupamos nas relações sociais marcam o para quê e o para quem de nossas ações e de nossos dizeres, sugerem modos de ser e de dizer, delineiam o que podemos (e não podemos) ser e dizer a partir desses lugares, modulando o discurso e os modos de apresentação do sujeito como tal, que vamos elaborando na dinâmica interativa.

Essa modulação, no entanto, é contraditória, na medida em que somos, ao mesmo tempo, nós mesmos e o "outro" do outro com quem estamos em relação. Nesse sentido, em um mesmo indivíduo articulamse dialeticamente dois lugares sociais distintos e complementares - 0 mesmo e o outro - que se afinam e se contrapõem, harmonizam-se e rejeitam-se, configurando, na tensão constitutiva da subjetividade, composições singulares, que se dão a ver na dinâmica interativa.

Assim focalizada, destacam Vigotski e Politzer, a personalidade não é um amálgama de processos psicológicos complexos e genéricos, mas o "drama" vivido nas relações interpessoais, em condições sociais específicas, por indivíduos peculiares em constituição. E é na dinâmica dos acontecimentos reais, singulares no espaço e no tempo, que a personalidade torna-se uma personalidade "para si", mediante 0 ato de terse mostrado aos outros como tal. Ou seja, somente em relação a outros indivíduos tornamo-nos capazes de perceber nossas características, de delinear nossas peculiaridades pessoais, de diferenciar nossos interesses das metas alheias e de formular julgamentos sobre nós próprios e sobre o nosso fazer.

Da perspectiva da constituição social, estudar o sujeito implica estudar relações entre sujeitos em suas condições sociais específicas de produção, e mais, lidar com a multiplicidade (eu/outro do outro) na unidade do próprio sujeito. Tal empreitada requer que nos coloquemos 
à margem das tentações da metapsicologia, difícil de superar nos quadros de nossa formação moderna.

No esforço de experimentar esse modo de abordagem dos processos de constituição de subjetividades, tenho-me acercado das narrativas - histórias ouvidas, lidas, cantadas, contadas, que nos falam da vida de personagens singulares, a partir de indicadores qualitativos, aparentemente casuais e internos a suas experiências (Canevacci1997).

Nas narrativas, vida e texto - duas formas do tecer que se entrelaçam - dão a ver, dão a ler as especificidades de vivências diferenciadas, nas quais os saberes, a emoção, os sentimentos experimentados de angústia e de raiva, os sonhos, os fantasmas, o amor, que muitas e muitas vezes escapam à observação objetiva, fundem-se em tramas e dramas irredutíveis uns aos outros.

Por outro lado, apesar de sua singularidade, as narrativas, conforme destaca Benjamin em seu célebre ensaio sobre "O narrador" (1987), têm duas características que não as encapsulam em si mesmas, e que Ihes permitem formar-nos, na medida em que nelas podemos viver nossas próprias vidas.

Narrar pressupõe uma comunidade de vida e de discurso entre o narrador e o ouvinte, fundada em uma tradição e memória comuns. Aquele que narra (com)partilha saberes e vivências nos quais seus ouvintes se re-conhecem e, pelo re-conhecimento, inserem-se na história que está sendo narrada, fazendo sugestões sobre sua continuação, vivendo essa continuação.

A possibilidade de compartilhamento da narrativa faz dela uma "obra aberta" (Gagnebin 1987). Ou seja, a narrativa conta sem dar explicações definitivas, admitindo diversas interpretações. Seu não-acabamento se apóia na plenitude do sentido e em sua profusão ilimitada, de tal modo que cada história dá ensejo a uma outra história, suscita outras histórias.

Central do Brasil, o filme de Walter Salles, foi uma dessas narrativas que me incitou a retomar a questão da constituição da subjetividade, pelo sentimento de comunidade de vida e de discurso que Dora, a professora aposentada, escrevedora de cartas, despertou na mulher professora, brasileira, que sou, marcada, como ela, pelas dificuldades do exercício e permanência numa profissão que, contraditoriamente, assalta e recompõe, a cada dia, o humano em nós.

Desde os primeiros momentos do filme, Dora grudou-se em mim, trazendo com ela a escola, embora nenhuma escola nele apareça. Foi 
como ausência, como negação - não acesso, não permanência, não aprendizado - que encontrei e li a escola dentro de seu enredo. Os efeitos perversos dessa ausência, numa sociedade que se diz "democrática" e "escolarizada", escancararam em mim nosso malogro e nossas possibilidades como profissionais de educação nesse final de milênio globalizado e desumanizado.

Dora, mulher, professora, mulher-professora, nos materializa como malogro e como possibilidade. Nela está o nosso salário depauperado que frustra projetos, desejos e necessidades, que nos impossibilita o acesso aos bens culturais que estão na base de nosso próprio fazer, que nos empurra para a periferia de nós mesmas e das cidades onde vivemos. Em seus gestos duros, em seu rosto amargo, estão vincadas a ausência de reconhecimento e a desvalorização social do nosso trabalho docente. Mas nela pulsam, ainda, o gesto do encontro, fundante da relação pedagógica, a dúvida ética, o desejo, que nos fazem humanas.

Nos corredores da Central do Brasil, entre desempregados, camelôs, policiais, plaqueiros, usuários dos trens, homens, mulheres, velhos e crianças, gente miúda e ordinária que consome e produz o cotidiano urbano caótico de um país cada vez mais pobre e excludente, Dora comercializa uma habilidade técnica, cujo domínio detém, graças à escolarização a que teve acesso: ela sabe escrever e se apresenta como escrevedora de cartas àqueles que ainda permanecem despossuídos da escrita ao final do milênio.

Nessa transação, Dora e seus clientes constituem-se reciprocamente, como escrevedora e analfabetos - duas faces de uma mesma e única moeda, em um único e mesmo mercado de trocas materiais e simbólicas. Articulados numa mesma trama, ela e eles compõem o direito e o avesso de uma mesma e única prática cultural, a escrita, e de uma única e mesma instituição social, a escola.

Dize-me o que conheces e eu te direi quem és! Ambas, escrita e escola, sob sua aparente neutralidade, são locus de produção de significados e de subjetividades, de relações de força e de transmissão de poder.

No mercado da sobrevivência, a escrita vira instrumento de trabaIho para a Dora professora e para Dora escrevedora. Do escrever, ela, que é duas (e mais outras tantas) em uma, retira sua sobrevida.

No mercado das trocas simbólicas, o domínio da escrita é poder que se erige sobre a privação de quem a ela não teve acesso. Pela escrita, a professora e a escrevedora exercem/exercitam o poder sobre aque- 
les que a elas recorrem. No entanto, um ponto decisivo as diferencia. Enquanto ao papel social de professora cabe garantir o acesso à escrita, derivando daí a legitimidade de seu poder, o papel de escrevedora só se assegura pela manutenção da privação do outro. Sem analfabetos a quem vender seu trabalho, a escrevedora sucumbe.

Reunindo, em si, dois sentidos diversos de uma mesma prática, Dora produz e vive, contraditoriamente, a negação recíproca de partes de si mesma: a professora logra a escrevedora e esta sobrevive no/pelo apagamento da professora.

Como Dora, nós, professores, também vivemos no fio da contradição: detemos a posse de alguns códigos, de algumas informações e saberes que nos são assegurados pelo sistema de ensino, que tanto nos autorizam a ensinar quanto nos possibilitam meios materiais de existência e de exercício do poder. Institucional e idealmente, estamos na escola para ensinar a alunos que, por não saberem, estão ali para aprender. No entanto, essa escola que nos legitima o exercício do ensino deita suas raízes em tempos remotos, quando foi sendo engendrada a cisão entre educação e educação escolar.

Se de início a educação foi vivida como vida coletiva, em que os saberes e modos de ser eram compartilhados entre todos e dominados por todos, com a divisão social do trabalho e do poder, os saberes, os processos de aprender e de ensinar tornaram-se diferenciados e especializados, tornando-se privativos de alguns grupos em detrimento de outros. O ensinar foi passando gradativamente ao encargo de profissionais especializados para desenvolvê-lo, ocupando espaços e tempos delimitados e sistematizando-se através de regras e princípios. Foi nesse processo de cisão e expoliação que o profissional de educação começou a ser gestado, seja na forma do professor de primeiras letras, prestigiado em algumas culturas, relegado à probreza em outras, seja como o educador, o mestre do domínio das palavras e das artes da guerra, tão necessárias ao exercício do poder (Manacorda 1992).

Historicamente, foi-se configurando então, junto à educação indissociada das relações cotidianas, a atividade especializada e formalizada de ensino, que foi ganhando ao longo dos séculos um caráter propriamente escolar de transferência (e ao mesmo tempo de exclusão) dos saberes entre gerações. Esse é o contexto da nossa profissionalização, que se efetiva com a constituição dos sistemas nacionais de ensino, enraizada nas relações entre conhecimento e poder. 
A profissionalização e a remuneração do trabalho docente não aconteceram repentina nem tranqüilamente. Elas foram alvo de disputas e embates, cuja sistematização remonta aos enfrentamentos entre os filósofos - "sábios" - e os sofistas - "professores de sabedoria".

Além de procederem à passagem da reflexão cosmológica, em torno da procura do princípio (arché) de todas as coisas, para a reflexão predominantemente antropológica, os sofistas elaboraram teoricamente o ideal democrático dos comerciantes enriquecidos e marginalizados, pela aristocracia, das decisões sobre as coisas da cidade. Redefinindo a virtude como algo que pode ser conquistado pelo cidadão da pólis, e portanto ensinada por meio de exemplos de conduta moral e de decisões políticas, valorizaram na figura do "mestre", apesar do repúdio da aristocracia, a possibilidade de capacitar "o outro" ao domínio da retórica habilidade necessária à participação política. Criaram a remuneração para esse serviço e sistematizaram o ensino. Com sua presença fundaram a distinção, que se prolonga até hoje, entre o "educador" - alguém da estirpe do filósofo, o amante, o amigo da verdade - e o "professor" aquele que sofisma, aquele que se apropria do "saber" de outrem e se confunde com ele, sem explicitar sua voz de mediador. Distinção, que o velho ditado "quem sabe faz, quem não sabe ensina" também sintetiza, ilustrando, agora do outro lado - o dos homens do trabalho - a ambigüidade do lugar que temos, historicamente, ocupado.

Quando aceitamos o convite feito por Mario Manacorda (1992) para um rápido passeio pela educação nos séculos, acompanhamos e apreendemos não só a diversidade de objetivos de que a relação educativa formal se revestiu, de época em época, em função do real existente e de suas contradições, como também as configurações de que se revestiu a função docente e sua constituição política e social, imersa, ao longo dos séculos, na luta entre os homens-do-dizer e os homens-do-fazer.

Dois olhares em confronto, o do trabalho e o da contemplação, fitando o mesmo mundo a partir de mirantes diversos. Duas visões de mundo distintas, porque produzidas em condições distintas, cruzando-se, enfrentando-se...

Os homens da épeas, homens-do-dizer, como nos ensina Manacorda, possuem os bens materiais e detêm o poder. São educados para as tarefas do poder, que são o pensar, o falar e o defender "as coisas da cidade" (política). Conhecem as leis, dominam a escrita para poder registrá-las e podem (porque lhes é legitimado) explicá-las pelo discurso, dominam o manejo e uso 
das armas. Com leis e armas julgam e lhes é legitimada a possibilidade de expressar o julgamento, punem e lhes é legitimado o exercício da punição, defendem a cidade/defendem-se contra as ameaças.

Os homens da érga produzem e nada (ou pouco) possuem. Seu saber é o saber fazer, que se aprende fazendo. Conhecem as leis do que fazem e as que determinam e submetem o que fazem, mas não lhes é dada a possibilidade de participar de seu registro e de sua aplicação. Resistem a essas leis, pagando um preço: a vida e a voz, silenciadas pelas armas e pela escrita, apagadas da história oficial. Julgam o que fazem, o como fazem, o que fazem deles e com eles, o que vivem, mas não lhes é legitimado expressar seus julgamentos. São excluídos da participação "nas coisas da cidade". Para eles,

nenhuma escola inicialmente, mas só um treinamento no trabalho, cujas modalidades, que foram mostradas por Platão, são destinadas a permanecer imutáveis durante milênios: observar e imitar a atividade dos adultos no trabalho, vivendo com eles. (Manacorda 1992, p. 41)

Pelo poder, conhecimento e trabalho se opõem, embora sejam complementares nessa oposição: é o trabalho que, produzindo, possibilita a contemplação do mundo produzido.

$\mathrm{Na}$ luta secular entre os que falam e os que fazem, nosso conhecimento do mundo e o nosso ser no mundo vai se configurando. E, nesse sentido, conhecer é poder (controle, manutenção, proibição, punição) e luta (apropriação, transgressão, resistência). Poder que busca a cristalização, se possível, eterna. Luta interminável, que nem sempre leva à vitória, movida pelo desejo de estabelecer um outro modo de olhar - a utopia.

O conhecimento como poder e luta está inscrito nas instituições, está inscrito na constituição do profissional e da profissional de educação e, através dela, inscreve-se também na constituição singular de cada homem-professor e de cada mulher-professora. Na contradança entre fios e lados, registrada cuidadosamente ao longo dos tempos, em narrativas que guardam nossas tão remotas origens, tece-se a dimensão política do trabalho docente. "Eu, quem eu era? De que lado eu era?", pergunta-se (pergunta-nos) o personagem de Rosa (1980), como, também eu, pergunto a Dora e a mim - de que lado? - explicitando os enfrentamentos 
que vivemos em nossas relações com o trabalho, explicitando nossos modos de estar no mundo, explicitando nossos modos de viver o lugar social de professoras.

Entre os homens-do-dizer e os homens-do-fazer, nós educadores profissionais, nem sempre homens-do-dizer, mas a serviço deles, situamonos, ambiguamente, no viés do confronto.

Walter Salles, diretor do filme, e seus roteiristas, não nos poupam. Eles desmascaram o poder que preside as relações de Dora com seus clientes, desvelando seus efeitos em favor da permanência da exclusão e o jogo de dissimulação em que se oculta esse efeito.

Dora não escreve cartas. Ela transcreve, escreve dizeres, num fazer estritamente técnico que simula o gesto de quem escreve uma carta, pois a razão de ser de uma carta, que é chegar ao seu destinatário, que é ser lida por ele, está abortada a priori. Dora controla o destino dessas cartas: elas vão parar numa gaveta após serem lidas e ridicularizadas por ela, e isso nos choca.

A escrita que ela pratica e vende está esvaziada do seu sentido humano. Escrever, mais do que um modo de ação no mundo, mais do que uma possibilidade de dizer o que se pensa e o que se quer, mais do que uma possibilidade de interlocução, é a tarefa que the é possível no mercado de desigualdades. Nas suas mãos, a escrita, que ela ensinou um dia, apresenta-se esvaziada de sua dimensão humanizadora (ação constitutiva, que modifica, que transforma), é estranhamento, é mercadoria, é técnica que se vende, do mesmo modo que se vendem tantas outras coisas... Serve a uma ética de esmagamento do outro pelo engodo e a uma política de manutenção da exclusão.

Sua figura e seu gesto põem em questão o conhecimento detido por nós professores/professoras e as relações de produção de conhecimento e de constituição de subjetividades de que somos protagonistas. $\mathrm{O}$ que conhecemos? A quem/a quê tem servido esse conhecimento? $\mathrm{O}$ que ensinamos? Para quê, para quem?

Nós, professoras e professores, da mesma forma que Dora, simulamos relações de conhecimento sob a tarefa de ensinar, nossa mercadoria. Fingimos, muitas vezes acreditando, que compartilhamos com nossos alunos relações puramente cognitivas; que Ihes transmitimos informações neutras, cuja credibilidade vem de seu caráter científico; que Ihes possibilitamos o conhecimento de fatos ao Ihes ensinarmos definições. 
Também procuramos controlar os sentidos que se produzem na relação de ensino, e isso é parte de nosso papel social, através da determinação da perspectiva de onde devem ser vistos e ditos os fatos que apresentamos aos alunos em nossas aulas.

Como o fazemos? Através de que ações o fazemos ?

Nossas "aulas" se realizam predominantemente pela fala. O ensino materializado no falar professoral tem especificidades que nos permitem "prender os interlocutores no espaço do instituído" (Orlandi 1987, p. 32), conforme enumera Barthes (1988, p. 313-332).

O falar professoral é "uma fala pública", dirigida a um grupo bem definido - o dos alunos - que ocupa um lugar social hierarquicamente submetido ao do professor (por mais "democráticos" que sejamos). É portanto "uma fala de autoridade", à qual se pede clareza, nitidez, transparência.

Além disso, nós professores, a pretexto de expormos um saber, propomos um discurso que, raramente, é organizado por nós, a despeito de 0 assumirmos como nosso. Conforme analisa Eni Orlandi, pela posição que ocupamos na instituição escolar, nos apropriamos "do cientista e nos confundimos com ele" (1987, p. 21), sem explicitar nossa voz de mediadores. Por meio dessa estratégia, da qual raramente nos apercebemos, a voz do saber legitimado fala em nós e como tal, o que informamos se apresenta como de interesse e utilidade por si mesmo.

Como lugar de autoridade, de saber legitimado que vale por si mesmo, a fala professoral é também uma fala que pode ser resumida, “... privilégio que partilha com o discurso dos parlamentares". No resumo, pensamento e estilo são cindidos: "a 'forma', assim se pensa, é comprimível, e essa compressão não é julgada essencialmente prejudicial", pois o que importa são as definições, os sentidos supostamente homogeneizados que elas veiculam. A possibilidade mesma de resumo é um mecanismo cerceador da emergência de possibilidades de sentido, em favor da homogeneidade. (Barthes 1988, p. 315)

No cotidiano da sala de aula, embora nos utilizemos da "fala professoral" com segurança e destreza, desconhecemo-la. Moldamos nosso discurso pedagógico na "fala professoral" sem nos darmos conta de sua existência e características, naturalizando-as. No entanto, como lembra Barthes, a fala professoral é também lugar de exposição - "não é o saber que se expõe, o[s] sujeito[s] (expõem-se a penosas aventuras)" (p. 315). Na aula, falamos a nossos alunos, expomo-nos a eles e nosso 
recital é acompanhado pelo silêncio da compreensão. Esse silêncio, embora seja esperado, na medida em que tranqüiliza - não há sustos, não há dúvidas, não há perguntas sem resposta (Orlandi 1987, p. 30) contraditoriamente nos priva de indicadores de como foi, de como está sendo recebido nosso discurso, priva-nos de uma imagem, mesmo ofensiva, que nos constitua, como assinala Barthes.

Naturalizados em nosso fazer e desprovidos de uma imagem, nos vemos como o que está posto, como o que é assim mesmo, estagnamos - nosso malogro e suplício.

Embora a fala professoral não tenha como impedir a produção de sentidos outros, ela os silencia, cerceia sua circulação, na medida em que não deixa espaço para o outro dentro do discurso do professor, tampouco espaço para que o professor se coloque como ouvinte. (Orlandi 1987, p. 32)

Como Dora o faz com as cartas, a fala professoral dificulta a constituição dos interlocutores e do contexto como elementos da significação. Ela favorece a estagnação da vida no interior da escola. Continuamos a ensinar velhos conteúdos e saberes, alheios e surdos a questões e preocupações que estão no centro de nossas vidas cotidianas e das vidas de nossos jovens e crianças: violência, sexualidade, Aids, novas tecnologias, desemprego, "verdade", identidade, subjetividade, gênero, raça, etnia...

O filme e, dentro dele, Dora, nos mostram que não há lugar para ingenuidade. Se sua figura contribui para pôr por terra a aura de santidade, pureza, perfectibilidade moral, carinho e dedicação à criança, que, por décadas, compôs a imagem paternalista (ou maternal?) da profissão docente, também contribui para desvelar o autoritarismo autorizado de um saber legitimado sobre saberes emergentes. Sua figura líqüida, também, a ilusão liberal de que a educação poderia ser um campo situado fora do alcance das operações de mercado, uma espécie de refúgio dos seus efeitos mais perversos, que poderia diminuir, ou até mesmo nivelar as desigualdades por ele produzidas (Silva 1998).

Desvelando os percursos de nossa constituição profissional num lugar e tempo que são nossos, o filme e, dentro dele, Dora, nos colocam diante de um dilema: que professoras/professores estamos sendo, em tempos difíceis como os de hoje, quando a escola caminha para funcionar cada vez mais como empresa, sendo a educação, esvaziada de seu significado humano, sua mercadoria? Nesse processo de formação e nas relações de trabalho vividas, quem estamos sendo? Quem estamos chegando a ser? Ao tom de que diapasão temos nos afinado? 
Mas Dora encontra Josué, menino-pobre-sem-mãe-à-procura-do-pai. "Moleque." Um excluído ...

Dora, mulher-sozinha-professora-aposentada-que-vive-de-escrevercartas-na-Central. Mulher sem marido e sem filhos. Mulher sem pai. "Mentirosa."

\section{Encontro casual.}

Josué, pião sem fieira, que perdeu o prumo e, bamboleante, perdeu o movimento, sente medo, está só, precisa do pai, sai em busca dele.

Dora mente, engana, ri das palavras dos outros, vende Josué em troca de uma televisão com controle remoto, sonho de consumo de quinquiIharias modernosas.

O mercado excludente, de cujas sobras participam, mediatiza a constituição de ambos (e também a nossa) como excluídos - mercadoria descartável - e como predadores sem ética.

“Tudo tem limite, Dora”, alerta-a (alerta-nos) Irene, sua amiga, também professora, também aposentada.

Dora perde o sono. A dúvida em relação aos seus atos grita, agigantase dentro dela. Volta atrás e sai decidida, em busca de Josué. Expõe-se, arrisca-se, rompe o pacto que estabelecera e se lança com o menino numa viagem em busca do pai perdido, num gesto de reparação do feito e de si mesma.

Dora sai de si, deixando para trás casa, televisão, rotina... E quando se sai, nunca se sabe os riscos... Tem início sua viagem em busca do pai de Josué, em busca de si mesma, saberemos (nós e ela) depois - viagem a si mesma pelo/com o outro. Viagem em que, quilômetro a quilômetro, ela e Josué vão perdendo roupas, ônibus, dinheiro, as certezas, as máscaras em que se reconheciam.

"Mentirosa", grita-Ihe Josué, em desafio, tomando a palavra, denunciando-a no cinismo de suas mentiras, no seu desleixo, na sua indiferença, no seu desespero, na sua solidão, nas suas contradições... "Moleque", grita-Ihe ela, a exigir-lhe um respeito que não se produzira entre eles.

Quanto mais se distanciam do ponto de partida, mais se perdem de si mesmos. Famintos e desesperançados, sem rumo e sem fieira, desencontram-se, perdem-se um do outro e, em desespero, re-conhecem-se um no outro. Não mais os mesmos. Ele e ela marcados pela exclusão, pela perda de referências e pela busca desesperada de uma 
identidade, aprendem a olhar-se, aprendem a ouvir-se, aprendem a dizer-se um ao outro, aprendem a ser um com o outro, no coração de um outro país, feito de fé e fome, aridez e força, solidariedade e esperança (que se arranca não se sabe de onde). A singularidade no diverso, a "identidade" na alteridade.

O encontro casual reconfigura a vida de ambos.

$\mathrm{Na}$ relação com Josué, Dora transforma-se/é transformada/ transforma. Mediada por ele, Dora desconstrói-se, passo a passo, produzindo uma outra em si mesma, com os restos re-significados da mulher árida, cínica e amarga que era. O batom, o vestido, as cartas que são colocadas no correio marcam a passagem.

Resignificando-se a si mesma, ela aprende a re-significar o outro e a assumir um projeto com o outro. Afina-se aos tons de Josué. 0 "moleque", com que o nomeava, vai-se suavizando até dar lugar ao seu nome. A distância física entre ambos, vai sendo quebrada pelo roçar dos braços, pelo tocar das mãos, pelo abraço, pela foto que tiram juntos, pelas lágrimas compartilhadas.

Josué transforma/é transformado/transforma-se. Ele re-significa Dora e re-significa sua própria busca cega e obstinada pelo pai. De mentirosa, Dora passa a companheira de viagem, de segredos, de sonhos, de pequenas mentiras ("meu nome é Geraldo") de dúvidas "fico ou vou-me com ela".

Dora faz-se fieira que imprime movimento e vida ao pião, resgata-Ihe as referências, a história.

Josué devolve a Dora o pai perdido na adolescência, devolve-lhe a escrita, devolve-lhe as lágrimas, devolve-lhe o sentido humano da vida.

Dora e Josué fazem-se, refazem-se mutuamente: direito e avesso, avesso e direito de um só e mesmo bordado - a vida compartilhada. Juntos, mergulham nas contradições do seu tempo e do seu espaço, elaboram-no e elaboram-se, expondo-se aos efeitos de sentido possíveis que vão nascendo na trajetória que compartilham e nas relações que estabelecem com aqueles com quem se encontram. Constituem-se como intersubjetividade.

Apesar da hegemonia do empobrecimento do humano, ambos humanizam-se e nos humanizam com/em sua trajetória, dando a ver, na história que narram, que somos possibilidade. 
Se não há como negar nossa participação, como professoras, na reprodução alienante/alienada do caráter excludente das instituições e práticas capitalistas hegemônicas, e se não há como fugir à culpabilização que a acompanha (dos alunos e de nós mesmos), também não há como negar que há significados alternativos em circulação. Há práticas e experiências que mostram que a definição da educação como mercadoria e o indivíduo predador competitivo do mercado não são inevitáveis nem o único ideal de subjetividade. (Silva 1998, p. 9).

Alienados e carregados de tantas culpas, temos nós, professores e professoras, vagado entre o confessionário (mais em conta) e o divã (cada vez mais inacessível aos nossos bolsos furados), procurando purgá-las, ou buscado nos cursos, palestras e encontros, respostas, pistas e saídas para o mal que nos aflige.

No entanto, ao invés de pistas e saídas, o filme nos indica que o caso é mais para entradas, para mergulho nesse nosso cotidiano eivado de limites e de possibilidades, que são sua contraparte. Cotidiano no qual, produzindo nossa prática, nos produzimos professores e professoras, reproduzindo as mazelas e subjetividades dominantes no nosso tempo, mas também resistindo a elas, conscientes, ou não, desse processo, mediados/as por nossos múltiplos outros.

É aí, no cotidiano do nosso fazer-se, no acaso dos encontros, que estão os signos involuntários, que nos desafiam a decifrá-los, que nos roubam a paz, que nos forçam a procurar seus sentidos possíveis...

Encaminhado para publicação em maio de 2000

\section{A social constitution of the subjectivity. Notes about "Central do Brasil""}

ABSTRACT: During difficult times such as these, when schools work more and more like firms, losing their human meaning, their merchandise, What type of teachers are we being? In this process of formation and in working relationships experienced, who are we being? Who are we trying to become? How do we find ourselves? In this paper, in dialogue with Vygotsky, Bakhtin, Politzer and with Walter Sales' film - Central Station - I approach these questions, not to answer them but to face them in the singular dramas experienced by ourselves with our other self, in social relationships of exclusion and solitude, of inequality and violence of imposed modernization and prejudice. 


\section{Bibliografia}

BAKHTIN, M. Marxismo e Filosofia da Linguagem. São Paulo: Hucitec, 1986.

. Estética de la creación verbal. México: Siglo Veintiuno Ed., $1985,2^{\mathrm{a}} \mathrm{ed}$.

BARTHES, R. "Escritores, intelectuais e professores" In: O rumor da língua. São Paulo: Ed. Brasiliense, 1988, pp. 313-332.

BENJAMIN, W. "O narrador". In Magia e técnica, arte e política. Ensaios sobre literatura e história da cultura. Obras escolhidas (vol. 1). São Paulo: Ed. Brasiliense, 1987, pp. 197-222.

CANEVACCI, M. A cidade polifônica. Ensaio sobre a antropologia da comunicação urbana. São Paulo: Studio Nobel, 1997.

DEJOURS, C. A loucura do trabalho - estudo de psicopatologia do trabalho. São Paulo: Cortez/ Oboré, 1992.

FONTANA, R. A.C. Como nos tornamos professoras? Belo Horizonte: Ed. Autêntica, 2000.

GAGNEBIN, J. M. "Walter Benjamin ou a história aberta". In Magia e técnica, arte e política. Ensaios sobre literatura e história da cultura. Obras escolhidas (vol.1), Prefácio. São Paulo: Ed. Brasiliense, 1987, pp.7-21.

GUIMARÃES ROSA, J. Grande Sertão: Veredas. Rio de Janeiro: José Olympio, 1980.

MANACORDA, M. História da Educação - da antigüidade aos nossos dias. São Paulo: Cortez/Autores Associados, 1992.

ORLANDI, E. P. A linguagem e seu Funcionamento. As formas do Discurso. Campinas: Pontes, 1987.

POLITZER, G. Os fundamentos da Psicologia, Lisboa: Prelo, 1997.

SILVA, Tomaz Tadeu da. "A Escola Cidadã no contexto da globalização: uma introdução". In SILVA, H. da (org.) A escola cidadã no contexto da globalização. Petrópolis, RJ: Vozes, 1998.

VYGOTSKY, L.S. "Concrete Human Psychology”. In Psikhologya, Moscou, no 1, 1986, pp. 51-64. 